\title{
Serum concentrations of $\alpha 2$-macroglobulin, $\alpha 1$-antitrypsin, and C-reactive protein in dogs with suspected acute pancreatitis
}

\author{
Soyoung Park ${ }^{1, \uparrow}$, Hakhyun Kim ${ }^{2, \uparrow}$, Ji-Houn Kang ${ }^{2, *}$, Byeong-Teck Kang ${ }^{3}$, Mhan-Pyo Yang ${ }^{1, *}$ \\ ${ }^{1}$ Laboratory of Veterinary Internal Medicine, \\ ${ }^{2}$ Laboratory of Veterinary Internal Medicine and Neuroendocrinology, and \\ ${ }^{3}$ Laboratory of Veterinary Dermatology and Neurology, College of Veterinary Medicine, Chungbuk National University, \\ Cheongju 28644, Korea
}

\begin{abstract}
In canine acute pancreatitis (AP), inappropriate release and activation of zymogen proteases within the pancreas results in the consumption of serum antiproteases. The aim of this study was to examine whether the serum concentrations of $\alpha_{2}$-macroglobulin (A2MG), $\alpha_{1}$-antitrypsin (A1AT), and C-reactive protein (CRP) differ between dogs with AP and healthy dogs. Twenty healthy dogs and 20 dogs with AP were included in this study. Concentrations of A2MG, A1AT, and CRP were measured in the sera of healthy dogs and dogs diagnosed with AP. Serum A2MG and A1AT concentrations were significantly lower in dogs with AP than in healthy dogs, whereas the serum CRP concentration was significantly higher. In addition, the concentrations of A2MG and A1AT were significantly higher in AP survivors than in AP non-survivors, while the CRP concentration was significantly lower. However, in both AP survivors and non-survivors, the CRP concentrations showed a negative correlation with A2MG concentrations but not with A1AT. These findings indicate that serum antiproteases and CRP concentrations might be associated with the mortality rate of AP in dogs.
\end{abstract}

Keywords: C-reactive protein, pancreas, protease inhibitor, trypsin

*Corresponding author

Ji-Houn Kang

Laboratory of Veterinary Internal Medicine and Neuroendocrinology, College of Veterinary Medicine, Chungbuk National University, 1 Chungdae-ro, Seowon-gu, Cheongju 28644, Korea

Tel: +82-43-261-3691

Fax: +82-43-269-2595

E-mail: jhkang@chungbuk.ac.kr

Mhan-Pyo Yang

Laboratory of Veterinary Internal Medicine,

College of Veterinary Medicine, Chungbuk

National University, 1 Chungdae-ro,

Seowon-gu, Cheongju 28644, Korea

Tel: +82-43-261-3691

Fax: +82-43-269-2595

E-mail: mpyang@chungbuk.ac.kr

The first two authors contributed equally to this work.

ORCID:

Ji-Houn Kang,

https://orcid.org/0000-0001-8536-3027

Conflict of Interest

The authors declare no conflicts of interest.

Received: December 10, 2018

Revised: January 24, 2019

Accepted: February 4, 2019

\section{Introduction}

Acute pancreatitis (AP) in dogs is defined as acute inflammation and/or necrosis in the pancreatic or peripancreatic tissues [1]. Severe AP has a high mortality rate ranging from $27 \%$ to $58 \%$, although some cases are mild and self-limiting without complications [1-3]. In AP, zymogen proteases are inappropriately released and prematurely activated within pancreatic acinar cells, resulting in autodigestion [4]. Initial pancreatic acinar cell injury induces the release of various components including oxygen-derived free radicals, activating pancreatic proteases and phospholipase $\mathrm{A}_{2}$ [5]. These active pancreatic proteases are then released into the peritoneal cavity [6] as well as the circulation [1]. Circulating active proteases lead to a proinflammatory state associated with the activation of neutrophils and macrophages and release of cytokines, such as tumor necrosis factor-á, interleukin (IL)-1, and IL-6, which subsequently induce C-reactive protein (CRP) synthesis $[1,7,8]$.

Protease inhibitors, which form an important defense mechanism against developing AP, are found in tissue fluid and pancreatic tissue as well as serum [9]. The $\alpha$-globulin fraction of serum consists of main protease inhibitors: $\alpha_{1}$ antitrypsin (A1AT), $\alpha_{2}$-macroglobulin (A2MG), inter- $\alpha$-inhibitor, and $\alpha_{1}$-antichymotrypsin [10]. Of these antiproteases, A2MG may play a key role [11]. A2MG, a broad-specificity protease inhibitor, is able to bind to and clear pancreatic proteases as well as proteolytic enzymes released by neutrophils during inflammation [12]. Intravenously (IV) administered A1AT-trypsin complexes carry the enzyme to A2MG before elimination, suggesting that A1AT serves at least partly as a carrier [13]. IV infused trypsin is rapidly inhibited by $\mathrm{A} 2 \mathrm{MG}$, which binds to the trypsin and forms stable complexes [14]. Therefore, the objective of this study was to examine whether or not serum A2MG, A1AT, and CRP concentrations differ between dogs with AP and healthy dogs, and if so, whether there are differences in the serum concentrations of 


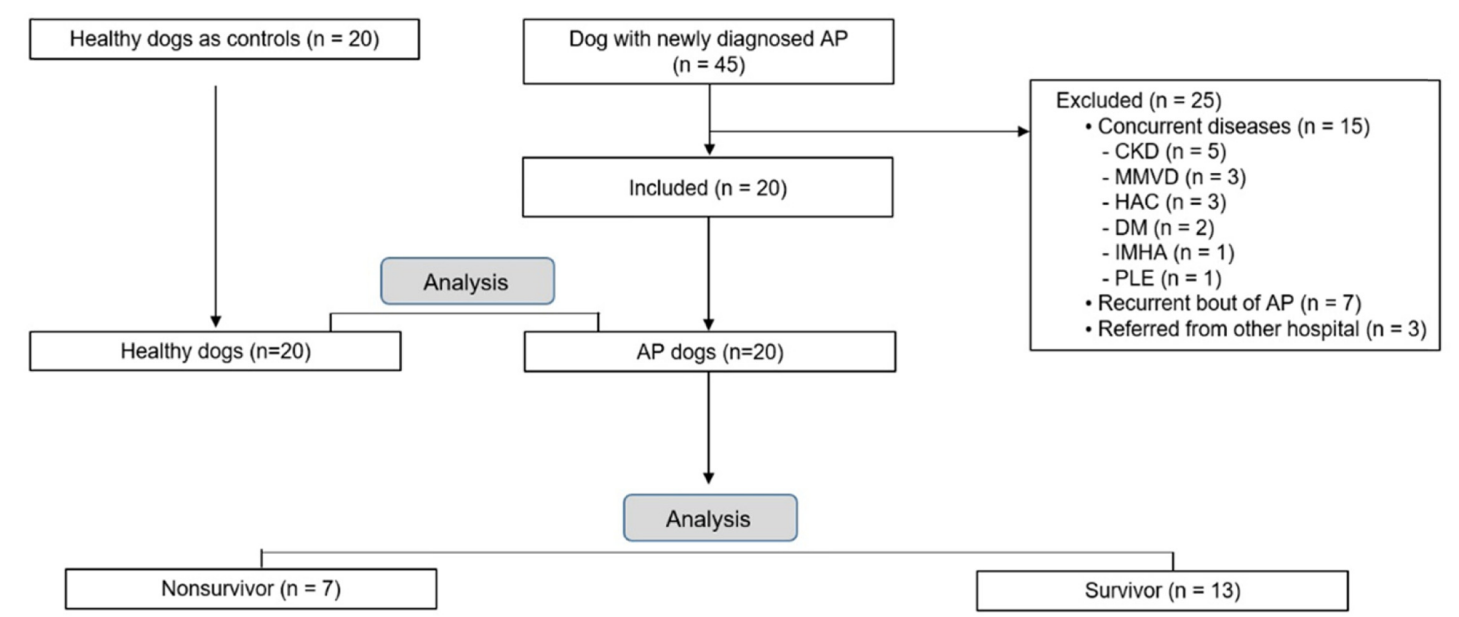

Fig. 1. Flow diagram of the enrollment of cases in this study. AP, acute pancreatitis; CKD, chronic kidney disease; MMVD, myxomatous mitral valve disease; HAC, hyperadrenocorticism; DM, diabetes mellitus; IMHA, immune-mediated hemolytic anemia; PLE, protein-losing enteropathy.

A2MG, A1AT, and CRP between AP survivors and AP nonsurvivors. In addition, the correlation between serum CRP concentrations and serum A2MG and A1AT levels in AP survivors and AP non-survivors was assessed.

\section{Materials and Methods}

\section{Animals and ethical issues}

The study approved by the University Ethics Committee (approval No. CBNUA-705-14-01), and the informed consent was obtained from the owners. Figure 1 shows a flow diagram describing the analysis of cases included in this study. Fourty-five dogs with newly diagnosed AP were included in this prospective, observational cohort study. Among these 45 dogs, twenty-five dogs with concurrent diseases, including chronic kidney disease $(n=5)$, myxomatous mitral valve disease $(n=3)$, hyperadrenocorticism $(n=3)$, diabetes mellitus $(n=2)$, immune-mediated hemolytic anemia $(n=1)$, or protein-losing enteropathy $(n=1)$, dogs with recurrent bouts of AP $(n=7)$ and dogs referred from other hospitals (diagnosed with AP and hospitalized for $>1$ days) $(n=3)$ were excluded on the basis of clinical data [15]. Thus, twenty client-owned dogs newly diagnosed with AP were enrolled in this study. They had not been treated with any medications associated with AP for at least 1 week before a diagnosis of AP was made. Twenty healthy, client-owned dogs were included as a control (Table 1). The healthy dogs were recruited when the dogs presented for health examinations and were enrolled on the basis of a normal clinical data.

Dogs with AP were classified as survivors $(n=13)$ and non-survivors $(n=7)$ by the attending clinician. Dogs were designated as survivors if they showed obvious clinical improvement and were discharged from the hospital. Evidences of the treatment in the survivors included resolving abnormal findings related with AP and negative result of
Table 1. Characteristics of dogs with AP and healthy dogs

\begin{tabular}{lcc}
\hline \hline \multicolumn{1}{c}{ Characteristics } & $\begin{array}{c}\text { Dogs with AP } \\
(\mathrm{n}=20)\end{array}$ & $\begin{array}{c}\text { Healthy dogs } \\
(\mathrm{n}=20)\end{array}$ \\
\hline Sex & 5 & 4 \\
Female & 4 & 4 \\
Neutered female & 4 & 3 \\
Male & 7 & 9 \\
Neutered male & $5.23 \pm 2.74 ; 2.1-10.8$ & $6.79 \pm 2.96 ; 3.8-12.0$ \\
Body weight $(\mathrm{kg})$ & $8.70 \pm 3.60 ; 3-14$ & $7.50 \pm 3.50 ; 2-15$ \\
Age (yr) & & \\
Breed & 2 & 5 \\
Miniature Schnauzer & 2 & 1 \\
Miniature Poodle & 2 & 1 \\
Maltese & 2 & 2 \\
Shih Tzu & 2 & 2 \\
Yorkshire Terrier & 1 & 0 \\
Pomeranian & 1 & 0 \\
Dachshund & 1 & 3 \\
Cocker Spaniel & 1 & 0 \\
Beagle & 2 & 4 \\
Pekinese & & \\
Mixed breed & & \\
\hline
\end{tabular}

Data are shown as mean \pm SE with ranges.

$\mathrm{AP}$, acute pancreatitis.

SNAP canine pancreatic lipase (cPL) test (IDEXX Reference Laboratories, Korea) [15]. Dogs were considered nonsurvivors if they died during hospitalization.

\section{Diagnosis of AP}

For a diagnosis of AP to be established $[8,16]$. the following 5 criteria had to be met: 1) a history of acute onset of signs compatible with AP such as anorexia, vomiting, weak- 
ness, or diarrhea; 2) an initial physical examination that included dehydration, icterus, fever, or abdominal pain; 3) abdominal ultrasound (Alpha 5; Aloka, Japan) findings suggestive of pancreatitis, including hypo/hyperechoic lesions, or mixed patterns, were recognized in pancreata that were potentially enlarged and irregularly shaped [8]. Furthermore, changes typically recognized as being secondary to pancreatitis, such as hyperechoic mesentery, localized free abdominal fluid, thickened duodenal or gastric wall, duodenal spasm, irritated appearance of the adjacent intestine, and dilated common bile duct, were also considered to be ultrasonographic evidence of AP; 4) increased specific (Spec) cPL concentrations (IDEXX Reference Laboratories) [15]. In the Spec cPL assays, concentrations $>400 \mu \mathrm{g} / \mathrm{L}$ were considered to be consistent with AP [17].

Healthy dogs were judged to be healthy based on the examination criteria of the previous paper [15].

\section{Treatment and grouping}

Treatment was conducted as currently recommended at the time of the study $[8,16]$. Aggressive fluid therapy was performed to combat the effects of disturbed pancreatic microcirculation that contributes to progression from mild to severe pancreatitis [18]. Supportive treatment consisted of low-molecular weight heparin, analgesics, antiemetics, broadspectrum antibiotics, and $\mathrm{H}_{2}$ receptor blockers [15]. In the case of assumption of pain, butorphanol tartrate (Butophan; Myungmoon Pharm, Korea; $0.2 \mathrm{mg} / \mathrm{kg}$ IV every $6 \mathrm{~h}$ ) or buprenorphine (NORSPAN patch; LTS Lohmann TherapieSysteme AG, Germany; $4 \mu \mathrm{g} / \mathrm{kg} / \mathrm{h}$ TD every 4 days) was administered [19]. Maropitant citrate (Cerenia; Pfizer, France), an antagonist of neurokinin 1 receptors, was administered $(1 \mathrm{mg} / \mathrm{kg}$ SC every $24 \mathrm{~h})$ as an antiemetic, and famotidine (Gaster; Dong-A ST, Korea), a $\mathrm{H}_{2}$ receptor antagonist, was also given $(0.5 \mathrm{mg} / \mathrm{kg}$ IV every $12 \mathrm{~h})$ [15]. Even though there is little evidence of bacterial involvement in the initiation of AP, the dogs received broad-spectrum antibiotics when there was evidence of pyrexia and neutropenia with a left shift. Nil per os was maintained until vomiting ceased. A small amount of water was supplied when vomiting ceased even if the antiemetic was discontinued. If there was no vomiting after water intake, the dogs were fed small amounts of commercial low fat diet (Gastro-intestinal low fat; Royal Canin SAS, USA) on the following day.

Dogs with AP were classified into "survivor" or "non-survivor" groups according to the previous report [15]. Evidences of the AP resolution included ameliorating symptoms related with AP and negative result of SNAP cPL test [14].

\section{Assays}

All serum samples from dogs with AP and healthy dogs were stored at $-80^{\circ} \mathrm{C}$ until use. Samples were analyzed in duplicate in a single run with commercially available caninespecific enzyme-linked immunosorbent assay (ELISA) kits for A2MG (Canine $\alpha_{2}$ Macroglobulin ELISA kit; MyBio-
Source, USA), A1AT (Canine $\alpha_{1}$ Antitrypsin ELISA kit; MyBioSource), and CRP (Canine CRP ELISA kit; Millipore, USA) according to the manufacturer's instructions. For A2MG, both intra- and inter-assay coefficients of variation (CVs) were less than $10 \%$ with $1.0 \mathrm{ng} / \mathrm{mL}$ of sensitivity. For A1AT, both intra- and inter-assay CVs were less than $15 \%$ with $10 \mu \mathrm{g} / \mathrm{mL}$ of sensitivity. For CRP, intra- and inter-assay CVs were $\pm 3.5 \%$ and $\pm 2.7 \%$, respectively, with a sensitivity of $3.6 \mathrm{ng} / \mathrm{mL}$. Optical density was determined at $450 \mathrm{~nm}$ using an automated microplate reader (EPOCH; Bio Tek, USA).

\section{Statistical analyses}

Statistical analyses were carried out using a commercially available statistical software program (Prism 6.05 for Windows; Graph-Pad Software, USA). D'agostino-Pearson tests were performed to determine whether the data were normally distributed. Mann-Whitney $U$ tests were used to compare differences between dogs with AP and healthy dogs, and between AP survivors and AP non-survivors. We used Spearman's rank correlation tests to examine the correlation between serum concentrations of CRP and A2MG, and between CRP and A1AT, in dogs with AP. The $p$-values were calculated for 2-tailed tests, and the $95 \%$ confidence intervals (CIs) for the differences between medians were determined. For all analyses, values of $p<0.05$ were considered statistically significant. The data were expressed as medians with ranges.

\section{Results}

\section{Patient characteristics}

The AP dogs included 11 spayed females, 7 castrated males, and 2 intact males, while the control dogs included 8 spayed females, 7 castrated males, 3 intact males, and 2 intact females. The mean age (years) was not significantly different between the AP group $(8.70 \pm 3.60)$ and the healthy group (7.50 \pm 3.50$)$, or between survivors $(8.10 \pm 3.40)$, and non-survivors $(9.30 \pm 3.80)$ in the AP group. There was also no significant difference in body weight $(\mathrm{kg})$ between the AP group $(5.23 \pm 2.74)$ and the healthy group $(6.79 \pm 2.96)$, or between survivors $(4.58 \pm 2.03)$ and non-survivors $(5.89 \pm$ 3.29 ) in the AP group. Breeds in the AP group were Miniature Schnauzer $(n=5)$, Miniature Poodle $(n=2)$, Maltese $(n=2)$, Shih Tzu $(n=2)$, Yorkshire Terrier $(n=2)$, Pomeranian $(n=2)$, Dachshund $(n=1)$, Cocker Spaniel $(n=1)$, Beagle $(n=1)$, Pekingese $(n=1)$, and Mixed breeds $(n=2)$. The control healthy dogs included Miniature Schnauzer $(n=5)$, Miniature Poodle $(n=1)$, Maltese $(n=1)$, Shih Tzu $(n=2)$, Yorkshire Terrie $(n=2)$, Pomeranian $(n=2)$, Beagle $(n=3)$, and Mixed breed $(n=4)$.

Serum concentrations of A2MG, A1AT, and CRP in dogs with AP and healthy dogs

The median serum concentrations of $\mathrm{A} 2 \mathrm{MG}(95 \% \mathrm{CI}=-0.01$, $-0.02 ; p<0.001)$ and A1AT $(95 \% \mathrm{CI}=-0.34,-0.72 ; p<$ $0.001)$ were significantly lower in dogs with AP than in 
A

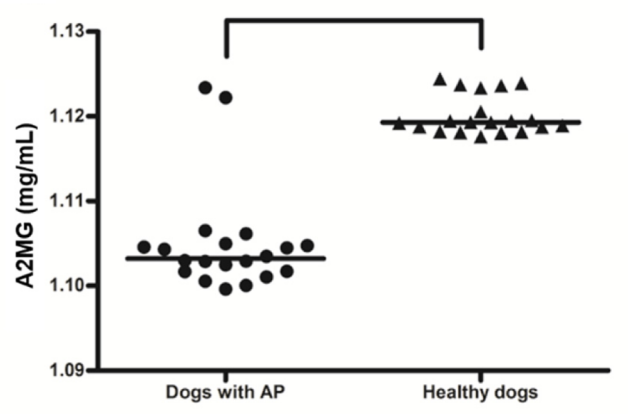

B

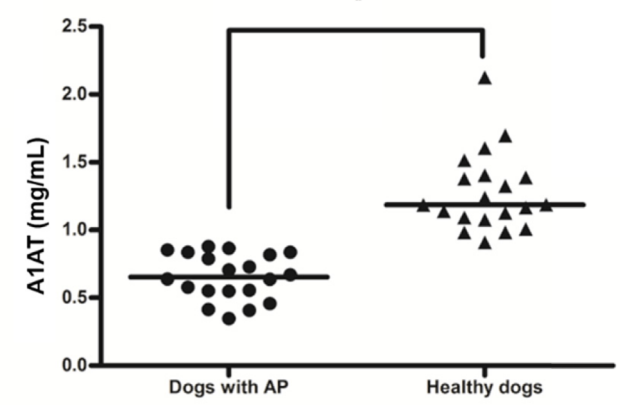

C

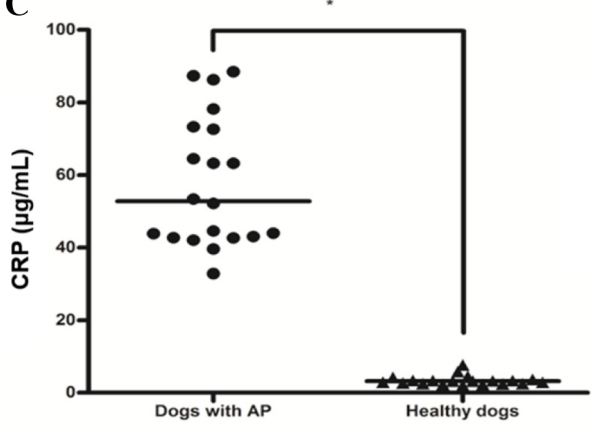

Fig. 2. Serum concentrations of (A) A2MG, (B) A1AT, and (C) CRP in dogs with AP $(n=20)$ and healthy dogs $(n=20)$. The horizontal lines indicate the medians. A2MG, $\alpha_{2}$-macroglobulin; A1AT, $\alpha_{1}$-antitrypsin; CRP, C-reactive protein; AP, acute pancreatitis. ${ }^{*} p<0.05$ (Mann-Whitney $U$ test).
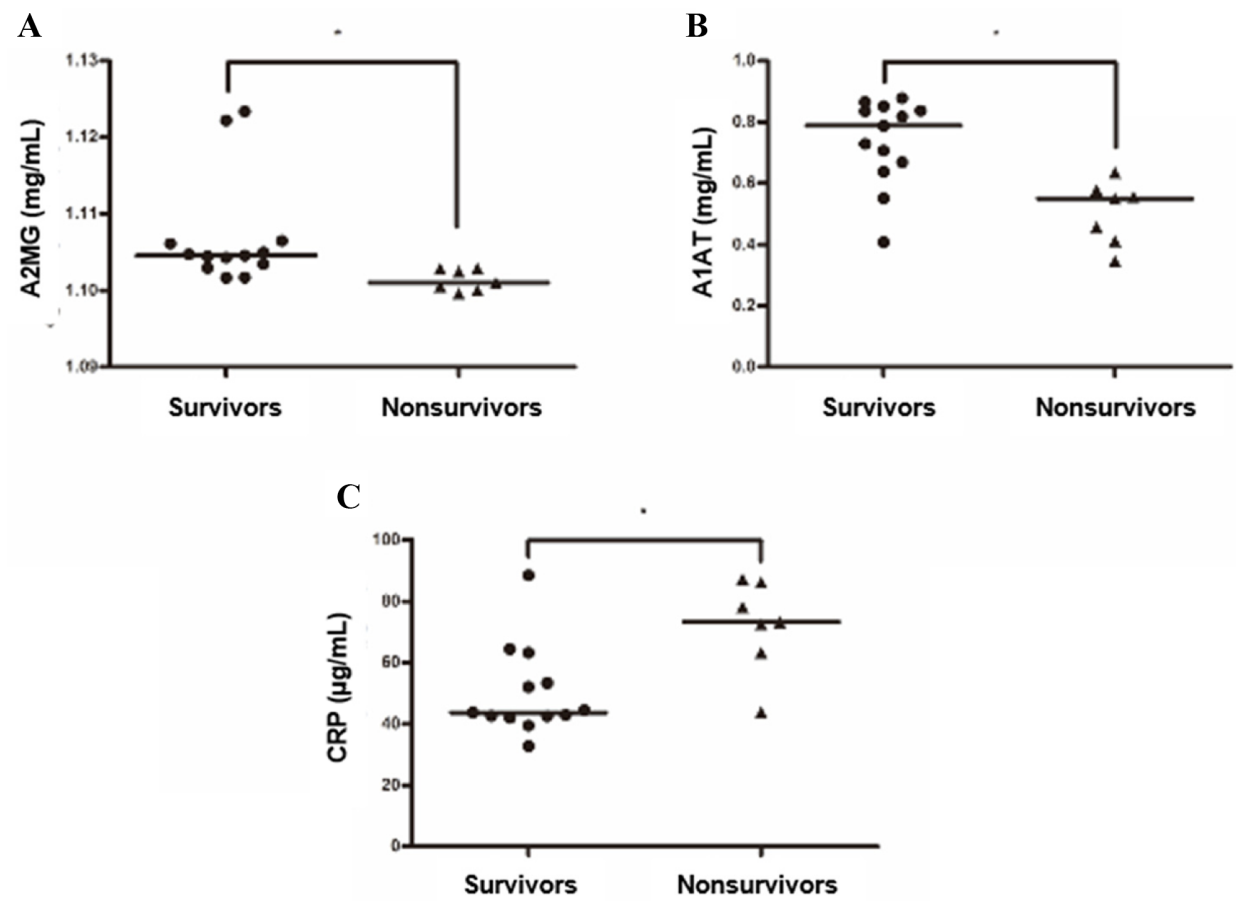

Fig. 3. Serum concentrations of (A) A2MG, (B) A1AT, and (C) CRP in AP survivors ( $n=13$ ) and non-survivors ( $\mathrm{n}=7)$. The horizontal lines indicate the medians. A2MG, $\alpha_{2}$-macroglobulin; A1AT, $\alpha_{1}$-antitrypsin; CRP, C-reactive protein; AP, acute pancreatitis. ${ }^{*} p<0.05$ (Mann-Whitney $U$ test). 
A

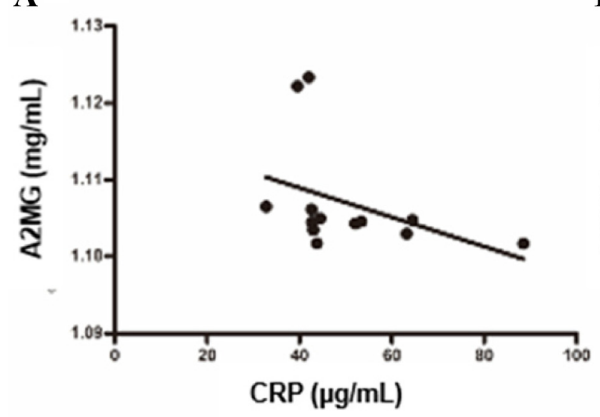

C

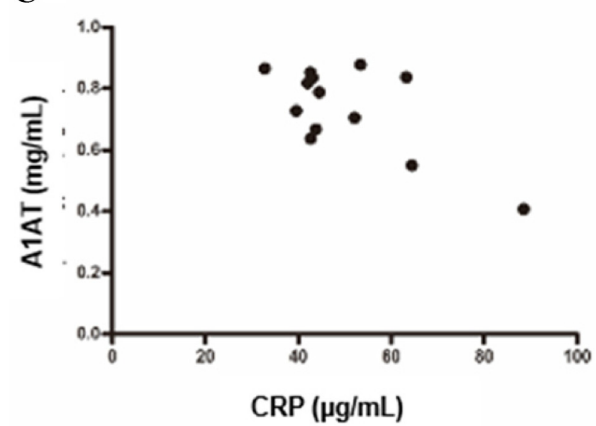

B

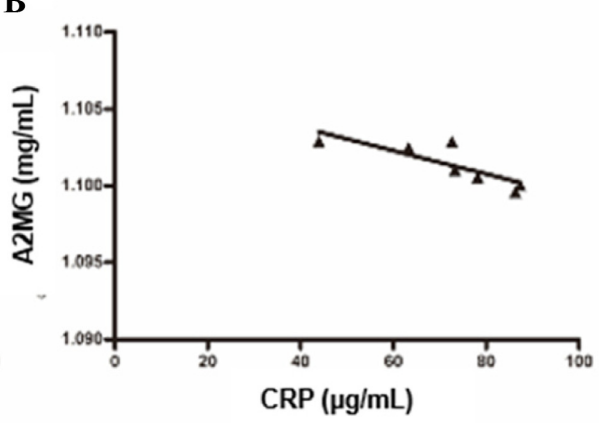

D

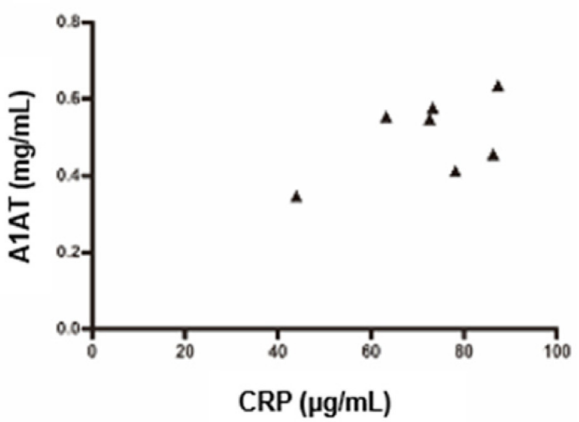

Fig. 4. Correlations between the serum concentrations of CRP and in (A) survivors $(n=13)$ and $(B)$ non-survivors $(n=7)$ in dogs with $\mathrm{AP}$, and correlations between levels of CRP and A1AT in (C) survivors and (D) non-survivors (Spearman's rank correlation test). A2MG, $\alpha_{2}$-macroglobulin; A1AT, $\alpha_{1}$-antitrypsin; CRP, C-reactive protein; AP, acute pancreatitis.

Serum concentrations of A2MG, A1AT, and CRP in AP survivors and AP non-survivors

Compared with AP non-survivors, the median serum concentrations of A2MG and A1AT $(95 \% \mathrm{CI}=0,0.01 ; p=0.002$ and $0.79,0.55 ; p=0.0043$, respectively) were significantly higher in AP survivors (Fig. 3A and B), whereas those of CRP $(95 \% \mathrm{CI}=-4.56,-18.42 ; p=0.0112)$ were significantly lower (Fig. 3C).

Correlations between CRP and A2MG and between CRP and A1AT in dogs with AP

In AP survivors, the serum concentration of CRP showed a negative correlation $(r=-0.6923 ; p=0.0087)$ with the serum A2MG concentration (Fig. 4A). In AP non-survivors, there was also a negative correlation $(r=-0.9286 ; p=0.0067)$ between the serum concentration of CRP and that of A2MG (Fig. 4B). However, CRP showed no correlations with the serum A1AT concentration ( $r=-0.3846 ; p=0.1944$; Fig. 4 C) in AP survivors and with A1AT $(r=0.4286$; $p=0.3536$; Fig. 4D) in AP non-survivors.

\section{Discussion}

Several studies evaluated the concentrations of $\alpha$-macroglobulin in AP and observed low serum $\alpha$-macroglobulin concentrations in dogs with spontaneous AP [20] or experimentally-induced AP [21], and in humans with AP [6, 22]. In agreement with these reports, our study revealed that the serum concentrations of A2MG were downregulated in dogs with AP. This can be ascribed to the consumption of the A2MG during AP, as supported by studies in which $30 \%$ of plasma A2MG in patients with AP was detected in complex with proteases [23]. We also found that serum A2MG concentrations in AP non-survivors were lower than those of AP survivors. No correlations have been reported between serum $\alpha$-macroglobulin concentrations and the severity of spontaneous AP in dogs [20]. However, serum concentrations of A2MG in humans with severe AP showed greater decreases compared to humans with mild AP during hospitalization $[6,24]$. In addition, a reduction in serum A2MG was reported previously to be correlated with outcome in human AP [25]. These findings suggest that low concentrations of serum A2MG in AP dogs may also result from consumption of $\mathrm{A} 2 \mathrm{MG}$ and that low levels of serum A2MG are predictive of a severe disease course of AP.

In the present study, serum A1AT concentrations were downregulated in dogs with AP. Serum A1AT concentrations were also lower in AP non-survivors compared with AP survivors. These results were supported by studies in humans that demonstrated lower serum concentrations of A1AT and a delay in rapid rises in serum A1AT concentrations and trypsin inhibitory capacity in severe AP compared to mild AP, suggesting the failure of patients with a severely compromised immune system to mount an inflammatory response [22]. However, these findings are contradicted by another report in which circulating concentrations of A1AT in humans 
with severe AP were higher than those in mild AP [24]. In addition, a subsequent clinical study found that serum concentrations of trypsin 2-A1AT complexes were higher in AP patients than normal controls, and suggested that trypsin 2A1AT complexes reflect AP-induced release of active trypsin 2 into circulation [26]. This report also suggested that serum trypsin 2-A1AT complex concentrations were more useful in predicting a severe course of disease at presentation than trypsinogen 2 and amylase concentrations [26]. Even though the serum concentrations of trypsin-antitrypsin complexes were not measured in this study, the finding of lower serum concentrations of A1AT in AP dogs compared to healthy dogs, and AP non-survivors compared to AP survivors, might be indicative of the active formation of trypsin 2-A1AT complexes and subsequent consumption of A1AT in AP dogs, which would be expected to be more excessive in dogs with severe AP and poor prognosis.

In human and veterinary medicine, it was proposed that fatal systemic pancreatitis arises from excessive leukocyte activation with the release of secondary mediators such as proinflammatory cytokines $[1,27]$. CRP, the acute phase reactant, is synthesized by the liver in response to inflammation, infection, or tissue destruction. The serum concentration of CRP was reported to be increased in human subjects with AP [11] as well as in dogs with other inflammatory and infectious diseases, including experimentally-induced [28, 29] and spontaneous AP [2]. This is consistent with our results that serum concentrations of CRP were upregulated in dogs with AP. In the present study, serum CRP concentrations were also higher in AP non-survivors compared with survivors. In human medicine, Serum concentration of CRP was reported to be correlated with the severity of disease $[9,30]$ and organ dysfunction in patients with AP [31]. This association is not restricted to AP, as elevated concentrations of serum CRP upon intensive care unit admission were correlated with an increased risk of organ failure and death [32]. Therefore, CRP is considered the gold standard serum marker for predicting severity of AP in humans [9]. Although CRP has not been evaluated with respect to severity of disease in AP dogs, our finding of high concentrations of serum CRP in AP non-survivors shows that, as in humans, serum concentrations of CRP might be useful for monitoring clinical progression and response to therapy in dogs with AP [10].

Our study showed that serum concentrations of CRP and A2MG were inversely correlated, whereas those of CRP and A1AT were not. Synthesis of CRP by the liver is largely regulated by IL-6 [33], and administration of recombinant human IL-6 in rats led to increased hepatic A2MG messenger RNA levels [34]. Conversely, CRP induces the rapid releases of cytokines including IL-6 and IL-1 [35], which accelerates the secretion of A2MG [19, 36, 37]. IL-1 $\beta$ and IL-6 were reported to be high in AP dogs compared with healthy dogs [8]. Thus, correlations between serum levels of A2MG and CRP might be explained by changes in the serum levels of cytokines, including IL-1 or IL-6. Further examination of the associa- tion between cytokines (IL-1, IL-6, and IL-10) and the production of $\mathrm{A} 2 \mathrm{MG}$ and $\mathrm{CRP}$ is required to determine whether cytokines influence the balance between A2MG and CRP in dogs with AP.

This study had several limitations. One was that a small number of dogs with AP were enrolled in this study, which can produce false-positive results or allow over-estimation of the magnitude of an association. Therefore, the data must be interpreted carefully. In addition, this study is that serum samples were not collected from each patient during hospitalization for consecutive days. Because the concentrations of CRP, A1AT and A2MG levels could be changed with time after inflammatory stimulation and differently altered along with the time period [38]. A final limitation of the present study was that there was no histopathologic confirmation of $\mathrm{AP}$, but histopathology can be invasive and expensive, and need general anesthesia in sick dogs [38].

Taken together, our study showed that dogs with AP had low serum concentrations of A2MG and A1AT and high serum concentrations of CRP. AP survivors showed increases in the serum concentrations of $\mathrm{A} 2 \mathrm{MG}$ and $\mathrm{A} 1 \mathrm{AT}$, and decreases in the levels of CRP. Therefore, these findings indicate that serum antiproteases and CRP concentrations might be associated with the mortality rate of AP in dogs. In addition, the magnitude of the decrease or increase in serum concentrations of A2MG, A1AT, and CRP might be useful in monitoring clinical progression and response to therapy in dogs with AP. Further studies to confirm these results are required.

\section{Acknowledgments}

The authors would like to thank all the owners of the dogs included in this study. This research was supported by the Basic Science Research Program through the National Research Foundation of Korea, which was funded by the Ministry of Science, ICT and Future Planning (NRF-2016 R1A1A1A05005395).

\section{References}

1. Mansfield C. Pathophysiology of acute pancreatitis: potential application from experimental models and human medicine to dogs. J Vet Intern Med 2012;26:875-887.

2. Holm JL, Rozanski EA, Freeman LM, Webster CRL. Creactive protein concentrations in canine acute pancreatitis. $\mathrm{J}$ Vet Emerg Crit Care (San Antonio) 2004;14:183-186.

3. Pápa K, Máthé A, Abonyi-Tóth Z, Sterczer A, Psáder R, Hetyey C, Vajdovich P, Vörös K. Occurrence, clinical features and outcome of canine pancreatitis (80 cases). Acta Vet Hung 2011;59:37-52.

4. Steiner JM. Canine pancreatic disease. In: Ettinger SJ, Feldman EC (eds.). Textbook of Veterinary Internal Medicine. 7th ed. pp. 1695-1704, WB Saunders Company, Philadelphia, 2010.

5. Ernster L. Biochemistry of reoxygenation injury. Crit Care Med 1988;16:947-953. 
6. Domínguez-Muñoz JE, Carballo F, García MJ, Miguel de Diego J, Gea F, Yangüela J, de la Morena J. Monitoring of serum proteinase--antiproteinase balance and systemic inflammatory response in prognostic evaluation of acute pancreatitis. Results of a prospective multicenter study. Dig Dis Sci 1993;38:507-513.

7. de Beaux AC, Ross JA, Maingay JP, Fearon KC, Carter DC. Proinflammatory cytokine release by peripheral blood mononuclear cells from patients with acute pancreatitis. Br J Surg 1996;83:1071-1075.

8. Paek J, Kang JH, Kim HS, Lee I, Seo KW, Yang MP. Serum adipokine concentrations in dogs with acute pancreatitis. J Vet Intern Med 2014;28:1760-1769.

9. Wilson C, Heads A, Shenkin A, Imrie CW. C-reactive protein, antiproteases and complement factors as objective markers of severity in acute pancreatitis. Br J Surg 1989; $76: 177-181$

10. Geokas MC, Van Lancker JL, Kadell BM, Machleder HI. Acute pancreatitis. Ann Intern Med 1972;76:105-117.

11. Mayer AD, McMahon MJ, Bowen M, Cooper EH. C reactive protein: an aid to assessment and monitoring of acute pancreatitis. J Clin Pathol 1984;37:207-211.

12. Petersen CM. Alpha 2-macroglobulin and pregnancy zone protein. Serum levels, alpha 2-macroglobulin receptors, cellular synthesis and aspects of function in relation to immunology. Dan Med Bull 1993;40:409-446.

13. Balldin G, Laurell $\mathrm{CB}$, Ohlsson K. Increased catabolism of alpha-Macroglobulins after intravenous infusion of trypsinalphal-antitrypsin complexes in dogs. Hoppe Seylers Z Physiol Chem 1978;359:699-708

14. Ohlsson K. Elimination of 125-I-trypsin alpha-macroglobulin complexes from blood by reticuloendothelial cells in dogs. Acta Physiol Scand 1971;81:269-272.

15. Kim DI, Kim H, Son P, Kang JH, Kang BT, Yang MP. Serum 25-hydroxyvitamin D concentrations in dogs with suspected acute pancreatitis. J Vet Med Sci 2017;79:1366-1373.

16. Mansfield C. Acute pancreatitis in dogs: advances in understanding, diagnostics, and treatment. Top Companion Anim Med 2012;27:123-132

17. Xenoulis PG, Steiner JM. Canine and feline pancreatic lipase immunoreactivity. Vet Clin Pathol 2012;41:312-324.

18. Bassi D, Kollias N, Fernandez-del Castillo C, Foitzik T, Warshaw AL, Rattner DW. Impairment of pancreatic microcirculation correlates with the severity of acute experimental pancreatitis. J Am Coll Surg 1994;179:257-263.

19. Koj A, Kurdowska A, Magielska-Zero D, Rokita H, Sipe JD, Dayer JM, Demczuk S, Gauldie J. Limited effects of recombinant human and murine interleukin 1 and tumour necrosis factor on production of acute phase proteins by cultured rat hepatocytes. Biochem Int 1987;14:553-560.

20. Ruaux CG, Atwell RB. Levels of total alpha-macroglobulin and trypsin-like immunoreactivity are poor indicators of clinical severity in spontaneous canine acute pancreatitis. Res Vet Sci 1999;67:83-87.

21. Murtaugh RJ, Jacobs RM. Serum antiprotease concentrations in dogs with spontaneous and experimentally induced acute pancreatitis. Am J Vet Res 1985;46:80-83.

22. Goodman AJ, Bird NC, Johnson AG. Antiprotease capacity in acute pancreatitis. Br J Surg 1986;73:796-798.
23. Lasson A, Ohlsson K. Protease inhibitors in acute human pancreatitis. Correlation between biochemical changes and clinical course. Scand J Gastroenterol 1984;19:779-786.

24. Banks RE, Evans SW, Alexander D, Van Leuven F, Whicher JT, McMahon MJ. Alpha 2 macroglobulin state in acute pancreatitis. Raised values of alpha 2 macroglobulin-protease complexes in severe and mild attacks. Gut 1991;32:430-434.

25. McMahon MJ, Bowen M, Mayer AD, Cooper EH. Relation of alpha 2-macroglobulin and other antiproteases to the clinical features of acute pancreatitis. Am J Surg 1984; 147:164-170

26. Hedström J, Sainio V, Kemppainen E, Haapiainen R, Kivilaakso E, Schröder T, Leinonen J, Stenman UH. Serum complex of trypsin 2 and alpha 1 antitrypsin as diagnostic and prognostic marker of acute pancreatitis: clinical study in consecutive patients. BMJ 1996;313:333-337.

27. Rinderknecht H. Fatal pancreatitis, a consequence of excessive leukocyte stimulation? Int J Pancreatol 1988;3:105-112.

28. Burton SA, Honor DJ, Mackenzie AL, Eckersall PD, Markham RJ, Horney BS. C-reactive protein concentration in dogs with inflammatory leukograms. Am J Vet Res 1994; 55:613-618.

29. Caspi D, Snel FW, Batt RM, Bennett D, Rutteman GR, Hartman EG, Baltz ML, Gruys E, Pepys MB. C-reactive protein in dogs. Am J Vet Res 1987;48:919-921.

30. Puolakkainen P, Valtonen V, Paananen A, Schröder T. Creactive protein (CRP) and serum phospholipase $\mathrm{A} 2$ in the assessment of the severity of acute pancreatitis. Gut 1987; 28:764-771.

31. Rau B, Steinbach G, Baumgart K, Gansauge F, Grünert A, Beger HG. Serum amyloid A versus C-reactive protein in acute pancreatitis: clinical value of an alternative acute-phase reactant. Crit Care Med 2000;28:736-742.

32. Lobo SM, Lobo FR, Bota DP, Lopes-Ferreira F, Soliman HM, Mélot C, Vincent JL. C-reactive protein levels correlate with mortality and organ failure in critically ill patients. Chest 2003;123:2043-2049.

33. Heinrich PC, Castell JV, Andus T. Interleukin-6 and the acute phase response. Biochem J 1990;265:621-636.

34. Geiger $\mathrm{T}$, Andus $\mathrm{T}$, Klapproth $\mathrm{J}$, Hirano $\mathrm{T}$, Kishimoto $\mathrm{T}$, Heinrich PC. Induction of rat acute-phase proteins by interleukin 6 in vivo. Eur J Immunol 1988;18:717-721.

35. Ballou SP, Lozanski G. Induction of inflammatory cytokine release from cultured human monocytes by C-reactive protein. Cytokine 1992;4:361-368.

36. Andus $\mathrm{T}$, Geiger $\mathrm{T}$, Hirano $\mathrm{T}$, Kishimoto $\mathrm{T}$, Tran-Thi $\mathrm{TA}$, Decker K, Heinrich PC. Regulation of synthesis and secretion of major rat acute-phase proteins by recombinant human interleukin-6 (BSF-2/IL-6) in hepatocyte primary cultures. Eur J Biochem 1988;173:287-293.

37. Gauldie J, Richards C, Harnish D, Lansdorp P, Baumann H. Interferon beta 2/B-cell stimulatory factor type 2 shares identity with monocyte-derived hepatocyte-stimulating factor and regulates the major acute phase protein response in liver cells. Proc Natl Acad Sci U S A 1987;84:7251-7255.

38. Newman S, Steiner J, Woosley K, Barton L, Ruaux C, Williams D. Localization of pancreatic inflammation and necrosis in dogs. J Vet Intern Med 2004;18:488-493. 